\title{
Assessment of the prophylactic efficacy of a crude aqueous extract of morinda lucida leaves on plasmodium falciparum infection of albino rats
} \author{
Ehihia Loveth Ude. \\ ${ }^{1}$ Department of Biotechnology, Ebonyi State University, Abakaliki, Nigeria \\ ${ }^{2}$ Department of Biotechnology, Federal University, Ndufu Alike-Ikwo, Nigeria \\ ${ }^{3}$ Department of Biochemistry, Ebonyi State University, Abakaliki, Nigeria
}

Oko Augustine Okpani ${ }^{1,}$, , Nweke Friday Nwalo ${ }^{2}$, Ugwu Okechukwu Ogbonnia ${ }^{3}$,

\section{Email address:}

okpanioko@gmail.com(O. A. Okpani)

\section{To cite this article:}

Oko Augustine Okpani, Nweke Friday Nwalo, Ugwu Okechukwu Ogbonnia, Ehihia Loveth Ude.. Assessment of the Prophylactic Efficacy of a Crude Aqueous Extract of Morinda Lucida Leaves on Plasmodium Falciparum Infection of Albino Rats. American Journal of Biomedical and Life Sciences. Vol. 1, No. 1, 2013, pp. 27-31. doi: 10.11648/j.ajbls.20130101.15

\begin{abstract}
A study on the prophylactic efficacy of a crude aqueous extract of the leaves of Morinda lucida on plasmodium falciparum was carried out using sixteen albino rats grouped into curative, suppressive, prophylactic and control ; A,B,C and D respectively. The rats were inoculated with the parasites and allowed for 21 days before $2 \mathrm{mls}$ of the extract was administered to each of the rats in group A twice daily for 3days, and for group B, $2 \mathrm{mls}$ was administered just once, 3hours before scarifying them, while for group C, $2 \mathrm{mls}$ was given twice daily for 3days before inoculation with the parasites, but group D were not given the extract. The results showed that the extract cleared the parasites in group A rats and did not allow its growth in group C rats, but did not suppress it in group B rats, while the control showed the ability of the parasites surviving in the rats. There was a significant at $(\mathrm{P}<0.05)$ weight loss by the rats in all the groups, following the inoculation of the parasite. It can be inferred therefore, that a crude aqueous extract of Morinda lucida has a prophylactic efficacy in addition to its curative activity against plasmodium parasites and could be used to mitigate the impact of plasmodium parasites.
\end{abstract}

Keywords: Maleria, Morinda Lucida, Plasmodium Falciparum

\section{Introduction}

Malaria is the world's most import parasitic disease especially when plasmodium falciparum is the causative agent (fisher and Bialek, 2002). Malaria is endemic in about 199 developing countries, accounting for about 40 to 55million DALYS (disability adjusted life years) and kills an estimated 1.2 million people each year in Africa (WHO, 2007). In Cameroon, Nigeria and sub-Saharan Africa, one in five children die before the age of five and $75 \%$ of these deaths are attributed to malaria (Encyclopedia, 1998). Pregnant women and children under five years of age are the most vulnerable. The soci-economic consequences of this disease are particularly dramatic in rural areas where poverty and malnutrition are more pronounced. In the absence of an effective vaccine, the fight against malaria depends on chemotherapy and the reduction and prevention of human, anopheles mosquito contacts through the use of insecticides treated bed nets, insecticides and environmental care (Awe, 1998). Resistance of Plasmodium falciparum to commonly used antimalaria drugs is increasing in Nigeria as in other parts of Africa (WHO, 2006). This has resulted in resurgence in transmission and an increase in adverse outcomes due to therapy failure. Hence, new highly efficacious antimalarial agents are urgently needed (WHO, 1998).

In an ancient literature, it was noted that plants were earlier studied from the viewpoints of their usefulness and this developed the birth rate of botanical science (Jethro, 1997). The method of using plant to enhance health must have come to the early man in the most unscientific way. Many people believe that they use their instincts to identify poisonous plants while some believe that there are external forces or invisible helpers who guided the early man to 
known what he could eat freely to keep fit (Jethro, 1997).

Different plant preparations have been used largely in traditional medicine for treatment of diseases such as malaria, pains, stomach-aches etc. Traditional medicine practitioners in the treatment of various ailments recognized these properties of some plants quite early. The typical examples of these medicinal plants such as Morinda lucida is used in the treatment of fever, carica papaya seeds, leaves or the stalks are used in the treatment of typhoid, Eupatorium odoratum and Aspila africana leaves are used in the treatment of wounds because of their anticoagulant properties, Ocimum Gradissuim leaf is used in the treatment of diarrhoea because of its richness in thyinol .Capsicum annum is a good source of vitamin C, Afromonum melegueta is used to speed up recovery from common colds (Iwu, 1999).

For thousands of years, plants have constituted the basis of traditional medicine systems and recently, natural products have been a good source of lead compounds for drug development. A good example against malaria is quinine (1), isolated from Cinchona_bark, which was used as a template for the synthesis of chloroquine and mefloquine. More recently, artemisinin (2) isolated from the Chinese plant Artemisia annua, has been used successfully against chloroquine resistant $P$. falciparum strains (Jethro, 1997). Morinda lucida_Benth (Rubiaceae) is a medium sized tree about $15 \mathrm{~m}$ tall and is widely used as a medicinal plant in West Africa, especially in Nigeria. The leaves are used as an ingredient of "fever teas", which are usually taken for the traditional treatment of malaria. The plant is also used as a general analgesic and laxative. A weak decoction of the stem bark is used for the treatment of severe jaundice (Asusu, 1990).

In Nigeria, a large number of plant species have been identified as antimalaria medicinal plants. Pure products have been isolated from some of these plants amongst which are those whose antimalaria activities are comparable to or more active than chloroquine on sensitive and resistant strains of Plasmodium falciparum (Awe,1998). It is in line with this, that it has become necessary to investigate the prophylactic effect of a crude aqueous extract of Morinda lucida over plasmodium falciparum in albino rats, thus the aim of this work.

\section{Materials and Methods}

The leaf of Morinda lucida were obtained in May, 2009 from a brimstone tree in Afikpo, Afikpo North Local Government Area of Ebonyi State, NIgeria and was authenticated by Prof. Onyekwelu, Head of Department of Applied Biology, Ebonyi State University, Abakaliki.

Sixteen adult female Sprague dawley strain albino rats were purchased from the Central Animal House, Department of Zoology, University of Nigeria Nsukka and were housed in wire mesh cages under standard environmental conditions with the provision of 12 hours light daily and were fed with growers mash feed. The animals were grouped into four namely Curative Group (Group A), Suppressive Group (Group B), Prophylatic Group (Group C) and Control Group (Group D ) .

The fresh leaves of Morinda lucida weighing 200g were washed with distilled water and squeezed thoroughly with $50 \mathrm{mls}$ of distilled water. The mixture was squeezed out with a handkerchief to get about $300 \mathrm{mls}$ of extract.

Plasmodium falciparum strain was purchased from Niger Foundation Hospital Enugu. About $0.2 \mathrm{ml}$ of the parasite was inoculated to each rat intraperitioneally in all the groups after 9 days of acclimatization and was monitored accordingly to undergo the 21 days of plasmodium lifecycle before the treatment commenced.

About $2.0 \mathrm{ml}$ of the extract was administered to each of the rats orally twice daily in groups, $\mathrm{A}$ and $\mathrm{C}$ while for the suppressive group $\mathrm{B}$, the extract were administered once (about 3hours) before scarifying them with proper monitoring of water and feed intake. Group D, which served as the control group was not administered with the extract.

At the end of the treatment and recovery period, each rat was anesthetized with chloroform, dissected and the blood sample was collected via the left ventricular cardiac puncture into EDTA sample collection container. About $0.3 \mathrm{ml}$ of whole blood was added to the test strip (Acon malaria P.F. Rapid Test Device) using a pipette alongside the addition of 3 drops of the phosphate buffer, after which the timer was started and avoidance of trapping air bubbles in the specimen was noted, waited for the coloured line to appear, and then the result was interpreted after 20 minutes.

\section{Results}

The results obtained were as shown below:

Table 1. Extraction yield

\begin{tabular}{ccccccc}
\hline Plant part & $\begin{array}{c}\text { Weight before } \\
\text { extraction } \\
(\mathbf{g})\end{array}$ & $\begin{array}{c}\text { Volume of water } \\
\text { used } \\
(\mathbf{m l})\end{array}$ & $\begin{array}{c}\text { Volume of extract } \\
(\mathbf{m l})\end{array}$ & $\begin{array}{c}\text { Weight of } \\
\text { residue } \\
(\mathbf{g})\end{array}$ & Differences (g) & Percentage (\%) \\
\hline leaves & 200 & 50 & 300 & 120 & 80 & 40 \\
\hline
\end{tabular}

There was about $40 \%$ yield of extract 
Table 2. Test for the presence of malaria parasite

\begin{tabular}{lllll}
\hline No of rats & GROUP A & Group B & Group C & Group D \\
\hline 1 & Negative & Positive & Negative & Positive \\
2 & Negative & Positive & Negative & Positive \\
3 & Negative & Positive & Negative & Positive \\
4 & Negative & Positive & Negative & Positive \\
\hline
\end{tabular}

All the rats in groups A and C tested negative for Plasmodium falciparum, while those in groups B and D tested positive for the parasite.

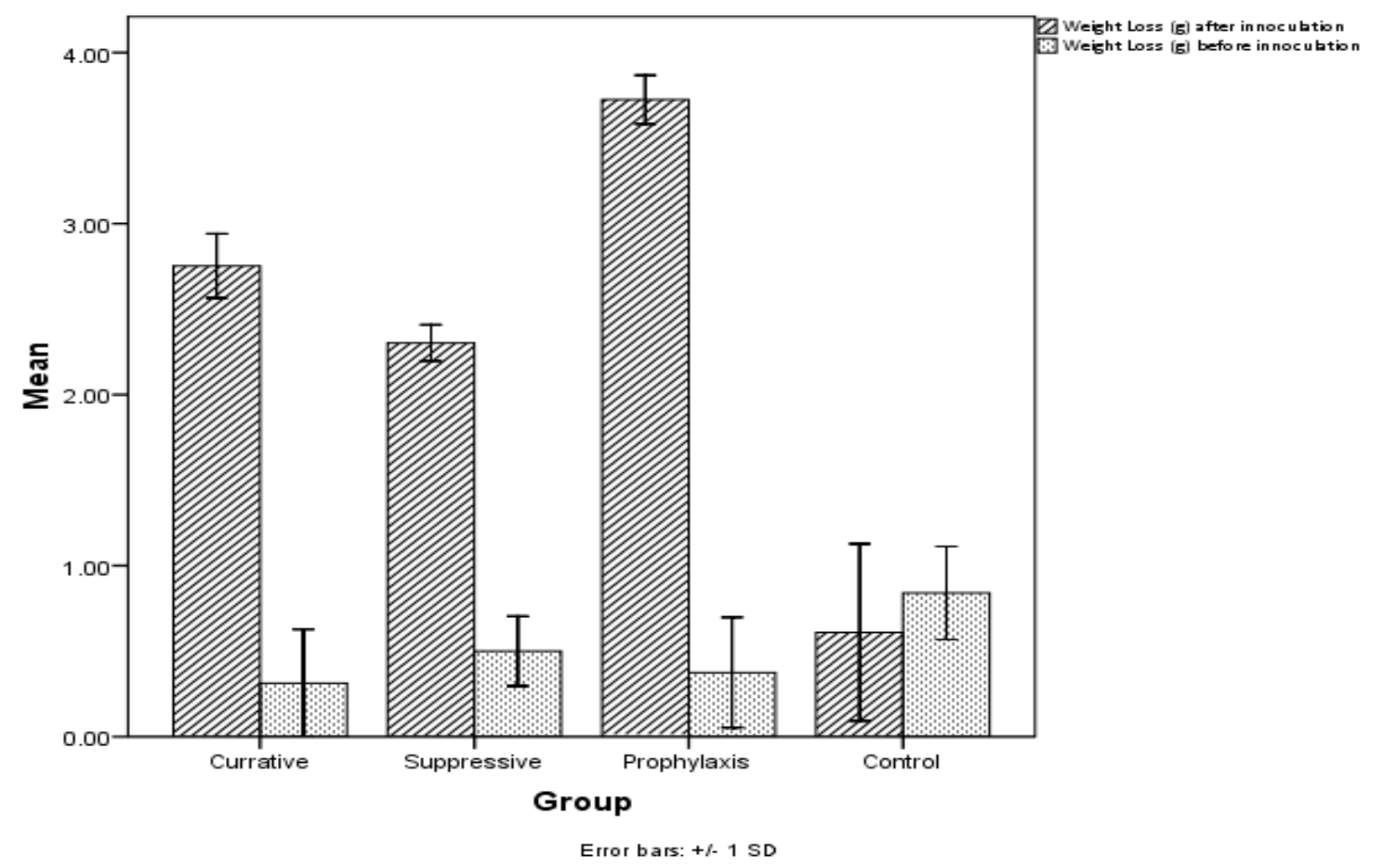

Fig 1. Bar chart illustrating the average weight of the rats in each group before and after inoculation of the parasite

\section{Discussion}

The aqueous extract of Morinda lucida gave a percentage yield of 40 . This showed that the constituents of the plant are semi soluble in water. The administration of the extract to test animals (group A-C) resulted in a significant decrease in their physical activities, feed and water intakes. Similar observation was made by Beet (2007), after treating mice with aqueous extract of this same plant. The reasons for these observations, though not very clear, could be linked to the changes in metabolic activities of the rats elicited by the phytochemical constituents of the plant. More so, there was a significant decrease $(\mathrm{P}<0.05)$ in the average body weights of the treated rats, relative to the control, which could be due to the decrease in feed and water intakes observed in the treated animals. In group A (the curative group), the extract was able to kill the parasites. This could be attributed to the antimalaira constituents of the extract e.g anthraquinone (Boesech et al., 2009).

For group B (the suppressive group), the administration of the aqueous extract of Morinda lucida to albino rats (inoculated with Plasmodium falciparum) revealed that the extract could not suppress the growth of the parasites, as the rats tested positive after treatment with the extract. This could be due to the fact that the rats were scarified immediately after 3hours of administration without allowing the extracts to elicit its antimalaria function in the rats studies has shown that it takes about six hours for crude aqueous extract of Morinda lucida to elicit its antimalaria effect reported (Raji, 1998).

In group $\mathrm{C}$ (the prophylactic group), it was observed that the extract prevented the survival of the parasite in the infected rats. The reason behind this finding is not clear but could be due to some constituents of the extract that increased immunological response in the treated rats against the malaria parasite. However, the prophylactic group was found to be anaemic, an observation that was shared by Beet ( 2007), who reported that red blood cell formation was inhibited in albino rats treated with extracts from Morinda lucida. The control group (D), which were not treated with the extract tested positive for plasmodium falciparium, proving the fact that the Plasmodium falciparum has the ability of growing in the albino rats. 


\section{Conclusion}

In conclusion, the assessment of the prophylactic efficacy of crude aqueous extract of Morinda lucida on Plasmodium falciparium in albino rats has revealed some more insight on the medicinal importance of the extract over Plasmodium falciparium infections. The study showed the efficacy of the extract being used as a prophylactic measure plasmodium falciparum.

\section{References}

[1] Akpantah, A. O., Oremous, A. A., Ajala, M. O., Nownha, C. C., and Okanlawon, (2003). The Effect of Crude Extract of Garcina Kola Seed on the Histology and Hormonal Milliew of Male Spragu-Dawley Rats Reproductive Organs. Nigeria Journal of Health and Biomedical Sciences, 2: 6-40.

[2] Asusu, I. U., and Chineme, C. N. (1990). Effect of Morinda lucida Leaf Extract on Trypanosome Brucei brucei Infection in Mice.Journal of Ethno pharmacology, 30: 31-307.

[3] Awe, S.O., and Makinde, J.M. (1998). Evaluation of Sensitivity of Plasmodium Falciparum to Morinda lucida Leaf Extract Sample Using Rabbit In Vitro Micro test Technique. India Journal of Pharmacology, 30: 51-53.

[4] Baldessarini, R. J. (2008). Drugs and the Treatment of Malaria, the Pharmacological Basis of Malaria Therapies, 6th Edition, Macmillan.New York $301-417$.

[5] Boesech, C., Ayala, F. J. and Wolfe, N. D. (2009). ABC of Medicinal plants, Nigerian Journal of Botany, 3: 1-24.

[6] Debayo, A.M., Ogbonna, E.O. and Raphael, E.A.(2005). Introduction to the Study of Herbal Medicine and Traditional Drugs 2nd Edition, Oxford Press, 240-251.

[7] De Souza, C., and Werner, W. (2005). Forms of Malaria in Tropical West African, Asian Journal of Andrologys, 7: 405-410.

[8] Encyclopaedia Wikipedia, (1998). 15th Edition, Wikipedia publishers. 88-106.

[9] Faciola, S. (2009).Comcopia: A Source book of Edible Plants. American Journal 4:23-43.

[10] Glass, J., and James, P. (2007). Malaria Prevention and Management. New England Journal of Physiological Sciences, 22: 129-134.

[11] Herbert, V. and Andrew A.A. (1980). Malignant Malaria. Journal of Gastroenterology, 15: 761-768.

[12] Iwu, C. O., and Adesogna, E. K. (1999). Anthraquinones and orwuwancin from Morinda lucida as possible Agents in Fasciolasis and Schistosomaiasis Control Fitoteripia , 55: 63-259.

[13] Jason, C. W. Peter, J.S. (2010). Reversal of Chloroquine Resistance in Plasmodium Falciparum using combinations of chemosensitizers. Antimicrobial Agent Chemotherapy. 45 3171-3174

[14] Jethro, S. O., and Makinde, J. M. (1997). Evaluation of
Anti-Diabetic property of Morina lucida leaves in Streptozotocin-debetic rats. British Journal of Pharmacology, 51: 1224-1321.

[15] Kloss, S. and Nelson, L. (1997). Structural Activity Studies:Analysis of Antileishmanial and Antimalaria Activities of anthraquinones from Morinda lucida. Planta Medicinal Journal, 65: 61-323

[16] Koumaglo,K., Gbeassor,M, and Nikabu,O.(1992). Effect of Three compounds extracted from Morinda lucida on Plasmodium Falciparum., Journal of Medicinal Plants Research, 3:319-323.

[17] Mbogo, C. M., Takang, E. E., Diffo, J.L., Pike, B.L., and Rosenthal, B, M. (2003). Spatial and Temporal Hetenogeneity of Anopheles Mosquito and Plasmodium Faciparum Transmission along the Kenvan Coast. American Journal of Tropical Medicine and Hygiene, 68: 315-334.

[18] Mutabingwu T. K. (2003). Treating Malaria during Pregnancy in Africa. 25: 66-73. African Journal of Medicine, 52:113-120.

[19] Nwaigwe, C. I., Adegunloye, B. J., and Sofola, O. A. (1997). Effect of Chloroquine on the Contractility of the smooth muscle of the rat uterus, trachea and urinary bladder. Basic clinical journal of pharmacology 8: 279-285.

[20] Obih, P.O., Makinde, J. M., and Laoye, J. O. (1998). Investigations of various extracts of Morinda lucida for Antimalarial actions on Plasmodium berghei berghie in Mice. African journal of medicine, medical science. 14: $9-45$.

[21] Oliver-Bever, B. (1986). Medicinal plants in Tropical West African Cambridge, 6th Edition Cambridge University press, 89-90.

[22] Olumide, S. Akinsomisoye, A. E., Yinusa, R., Toyin, M., And Akintola. E. (2008). Malaria in Pregnant Women and the Effect on infant Development; Implication for Growth, Resistance to Disease and Management. Journal of Ethnopharamacology, 12: 225-231.

[23] Peng, Q. I (2009). Biomedical Research of Medicinal Plants. Chinese journal of Eco-Agriculture, 17: 23-36.

[24] Prasad, S. D. (2009). Clastogenic effects of Glyphosate in Bone Marrow Cells of Swiss Albino Mice. Journal of Toxicology, 5: 138.

[25] Raddy, V. G., and Sinna, S. (2000). Chloroquine Poisoning Report of two Cases. American Journal of Physiology, 44: 1017-1020.

[26] Raji, V., Boloinwa, A. F. (1997). Antifertility activity of Quassia Amarai in the male Rats In Vivo Analysis. 64: 1067-1068.

[27] Raji, Y. Ifabunmi, S. O., Akinsomisoye O. S., Moralanyo, A. O., and Oloyo, A. K. (2005). Gonadal Response to Anti Psychotic Drugs, Chloropromaxine and Thioridazine Reversibly Suppress Testicular Functions in Albino Rats. International Journal of Pharmacology, 1: 92-287.

[28] Rich, S. M., Leendertz, F. H., Xu, G., Lebreton, M., and Aminake, M. N, (2009). The Origin of Malignant Malaria, National Academy of Sciences. A journal of physiology, 24: $50-62$. 
[29] Sittie, A. A., Lemminuh, E., and Oslen, C. E. (1999). Structure-Activity Studies: In Vitro Antileishmanial and Antimalaria Activity of Anthraquinone from Morinda lucida plant. British Medical Journal , 65 : 61-259.

[30] Snedecor, G. W., and Cochran, W. G. (1980). Statical Method, 7th Edition: Lowa State University Press, 215.

[31] Silverthorn, D. U. (2004). Pregnancy and Parturition in
Human Physiology. An

[32] Integrated Approach, 3rd Edition Pearson Education, Cambridge University Press, London. 821-828.

[33] World Health Organization (1998). World Health Organization Laboratory Manual for Examination of Human Semen and Semen-Cervical Mucus Interaction, 2nd

[34] Edition: Cambridge University Press, London 1-10 